
\title{
28 Research Square \\ Validation of the medium and short version of CENSOPAS-COPSOQ: A psychometric study in the Peruvian population
}

Martha R. Lucero-Perez ( $\nabla$ mlucero@ins.gob.pe)

Instituto Nacional de Salud

Iselle Sabastizagal

Instituto Nacional de Salud

Jhon Astete

Instituto Nacional de Salud

Miguel Angel Burgos

Instituto Nacional de Salud

David Villarreal-Zegarra

Instituto Nacional de Salud

Salvador Moncada

Instituto Sindical de Trabajo Ambiente y Salud

\section{Research Article}

Keywords: Psychometric, Occupational Health, Occupational Risks, Work, Peru.

Posted Date: March 15th, 2021

DOI: https://doi.org/10.21203/rs.3.rs-290093/v1

License: (1) This work is licensed under a Creative Commons Attribution 4.0 International License.

Read Full License 


\section{Abstract}

Background: The presence of psychosocial risks at work is associated with mental and physical health issues in workers. The study aim was to adapt the COPSOQ-ISTAS21 Medium-Version to the Peruvian context and to develop a Short-Version of the instrument.

Method: Cross-sectional design study. The COPSOQ-ISTAS21 Medium Version was used. A confirmatory factor analysis was performed to determine the internal structure of each subdimension (first-order) and dimension (second-order) using the Robust Maximum Likelihood estimation method, and classic fit indices in the literature (CFI, SRMR, RMSEA). Internal consistency was evaluated using the alpha and omega coefficients. A short version was developed based on the items with the highest factorial load and that reduce the factorial complexity.

Results: A total of 1707 participants were evaluated. In the confirmatory factor analysis, the goodness-offit indices for seventeen of the 20 one-dimensional models (subdimensions) were identified; two subdimensions could not be evaluated because they presented only two items. When conducting a multidimensional analysis, we identified that all second-order models presented optimal goodness-of-fit indices, except "psychological demands at work". The latter required adding four pairs of correlated errors to reach adequate fit values. Finally, a short version of only 31 items was designed from the items with optimal fit indices.

Conclusions: The new adapted versions of COPSOQ-ISTAS21 were renamed CENSOPAS-COPSOQ. The CENSOPAS-COPSOQ is an instrument with sufficient evidence of validity and reliability in its medium and short version, which is why its use is recommended in Peruvian work centers to identify the evaluation and prevention of psychosocial risks at work in Peru.

\section{Background}

Globalization, technological advances, and changes in the working market have modified the behavior and health of workers, and the perception of the occupational risks to which they are exposed [1]. Occupational psychosocial risks are defined as aspects related to the design and management of work, as well as those related to the social and organizational sphere that has the potential to produce psychological or physical harm [2]. Occupational psychosocial risks are a complex concept, as they involve such work content, workload, work rhythm, work schedule, control, environment and team, organizational culture, function, interpersonal relationships at work, role in the organization, development career, work-at-home interference [3]. Exposure to these psychosocial occupational risks increases the risk of physical and mental health issues, including heart disease and stress [4-7]. Also, psychosocial occupational risks can have effects on multiple indicators of the work environment and organizational functioning such as absenteeism and decreased productivity[8].

Most of the reforms of working conditions and studies on working conditions have been carried out in high-income countries. [1]. Particularly, Peru a middle-income country has enacted some laws to improve 
working conditions and reduce occupational psychosocial risks. Among them, Law 29783 on Occupational Health and Safety and its Regulations, where article $N^{\circ} 30$ indicates that employers must take into account the risks present in the workplace and specifically those related to the position or function of each employee[9]. Therefore, employers are responsible for evaluating the risks to which each worker is exposed and are in charge of ensuring the development and implementation of accident prevention and protection standards, based on these risks [9].

To comply with the existing legislation and improve the work environment of workers, it is necessary to have valid and reliable tools to assess the psychosocial risks at work in the workplace. Currently, there are different instruments to evaluate the occupational psychosocial risks [10], such as the Job Content Questionnaire (JCQ) [11]; Effort Reward Imbalance (ERI) Questionnaire [12]; COPSOQ (Copenhagen Psychosocial Questionnaire) [13]; General Nordic Questionnaire on Psychological and Social Factors at Work (QPS Nordic) [14].

Despite the variety of instruments for assessing occupational psychosocial risks, the COPSPQ has characteristics that differentiate it from most instruments [11], especially the ERI [12] and the JCQ [11]. Four advantages of the COPSPQ can be pointed out, compared to the rest of the instruments. First, it is not based solely on a theoretical framework that links occupational psychosocial risks, the work environment, and health, but uses a systemic approach [15]. Second, the COPSPQ has an epidemiological basis, which defines units of analysis in three sections (improve, maintain and promote) and allows a measure of assessment and intervention of the workplace [16]. Third, it incorporates indicators for specific sectors and occupations, which allows better specifying the levels of exposure to occupational psychosocial risk [16]. Finally, it is adaptable to all types of workplaces, since it was developed in the analysis and prevention of occupational hazards [16].

The COPSOQ-ISTAS-21 (Spanish version of the Copenhagen Psychosocial Questionnaire) presents three types of versions, however, two of them are the most used (medium and short); choosing for our study the medium version with 69 items, which is used in companies with more than 25 workers, and the short version that includes the most representative items and is used for companies with 25 or fewer workers. As has been shown, there is information that supports the usefulness of the COPSOQ-ISTAS-21 to measure the psychosocial risks at work in the workplace. This is why it is necessary to know the validity and reliability indicators of the COPSOQ-ISTAS-21 in the context of Peruvian companies.

\section{Methods}

\section{Design}

This is an instrumental study that aims to evaluate the evidence of validity and reliability of the CENSOPAS-COPSOQ medium version instrument, which originates from COPSOQ-ISTAS21 medium version. Also, it aims to develop and evaluate the validity and reliability of a short version of the CENSOPAS-COPSOQ. 


\section{Participants}

The sampling was non-probabilistic. The sample of this study consisted of workers from a list of companies registered at the National Superintendency of Tax Administration (SUNAT) with more than 25 workers. Workers over 14 years of age, with more than a month of service at the time of application of the questionnaire, literate, and who had signed the informed consent were included. Likewise, workers in the process of dismissal or immersed in administrative processes were excluded. The participants worked at six of the most important economic activities in Peru (Extractive, Manufacturing, Construction, Services, Transportation, and Communications).

Through a sample size calculation with a 95\% confidence level, a minimum size of 1604 workers was obtained. However, in the questionnaire application stage, a sample of 1707 workers was obtained; a fact that does not affect the validity of the study due to the nature of the research design.

\section{Instrument}

The COPSOQ is a Likert-type instrument of Danish origin, which was translated, adapted, and validated in Spain: being renamed COPSOQ-ISTAS-21, which assesses exposure to psychosocial risk factors at work considering working conditions in which this is done [17]. With response options ranging from always (5 points) to never (1 point). This instrument has 3 versions: a long (research), a medium (companies with more than 25 workers), and a short (companies with less than 25 workers). In this instrument, standardized scores can be obtained in a range from 0 to 100, in addition to grouping workers into terciles (green, yellow, red) classified as "most favorable for health", "intermediate" and "most unfavorable for health" respectively.

\section{Procedures}

The tests were applied to workers in workplaces with more than 25 workers according to the different economic activities and regions of Peru.

Also, all participants were given an informed consent that had to be signed voluntarily, if they wished to participate in the Study.

On the other hand, to perform the confirmatory factor analysis (CFA) and reliability analysis, the statistical program R Project was used.

\section{Analysis of data}

\section{Confirmatory factor analysis}

Twenty one-dimensional models were evaluated, and besides, the 6 second-order models with a factorial structure that encompass the 20 subdimensions mentioned above were evaluated. All these analyzes correspond to the average version of the COPSOQ-ISTAS-21 instrument (69 items). To conduct this analysis, the weighted least squares means and variance adjusted (WLSMV) was used. The assumptions 
of the model that WLSMV is that the data are ordinal and do not require compliance with the nonnormality of the data [18].

The different models of the COPSOQ-ISTAS-21 medium version were evaluated based on three steps. First, different indicators were used to determine the fit of each of the models (one-dimensional and second-order). The comparative fit index (CFI) was used, whose appropriate values are taken $\geq 0.90$. Likewise, the Standardized Root Mean-Square (SRMR) and the Root Mean Square Error of Approximation (RMSEA) with a confidence interval of $90 \%$ were used, which categorize as adequate value $<0.08$ [19]. The CFI compares the discrepancy between the covariance matrix predicted by the model and the observed covariance matrix [20]. That is, it compares the data obtained (observed covariance matrix) with how the data is expected to behave based on the fixed factorial structure (covariance matrix predicted by the model). The SRMR is a robust fit index that is the result of dividing the RMSEA by the standard deviation [21], allowing to adjust for the variability of the model. The RMSEA can be interpreted as the average level of error for each degree of freedom that the model has[21]. However, the RMSEA and SRMR are prone to rejecting correct models when the sample size is small or very heterogeneous [21]. Therefore, you must be flexible when you have small and heterogeneous samples within the measurements.

Second, all models must have at least three items to be evaluated, since it is the minimum number of items that allows an instrument to be stable [22]. Third, correlated errors were used to obtain a better fit and contextualize the original models (developed in other countries) to Peruvian contexts.

The new adapted versions of COPSOQ-ISTAS21 were renamed CENSOPAS-COPSOQ. The name change is justified due to the adaptation of the new items, evaluation of their measurement properties, and subsequent development of a short version.

\section{Reliability}

Based on the models identified in the factorial analysis, the reliability of the CENSOPAS-COPSOQ instrument was evaluated, medium version, through the analysis of internal consistency, reporting values of classical alpha (a) and categorical omega coefficient ( $\omega$ ) [23]. In both coefficients, the optimal values are $>0.70$.

\section{Development of a short version}

Based on the evaluated models of the CENSOPAS-COPSOQ medium version, it was sought to develop a short version aimed at evaluating psychosocial risks in public or private work centers with less than 25 workers. For this, the strategy of selecting the most representative items of each of the 20 subdimensions was proposed and gradually eliminating the items that contributed less variance or introduced factorial complexity to the model.

To develop this short version, five steps were proposed. First, by reducing the number of items, the 20 subdimensions would not be stable by themselves, so they were collapsed into only 6 one-dimensional models that encompass the 69 items of the original 20 sub-dimensions. Second, once the items were collapsed into 6 models, the items from each of the 20 original subdimensions were sequentially eliminated, until adequate fit indices were reached (CFI $\geq 0.90 ; \mathrm{RMSEA}$ and SRMR $<0.08)$. During the 
elimination of the items, we tried to keep those items that were more representative (with a higher factor load) and had less complexity (without correlated errors). Third, in order not to eliminate items unnecessarily and end up partially evaluating the construct, it was sought that within the 6 onedimensional models of the short version of the CENSOPAS-COPSOQ there would always be between one or two of the items of the 20 sub-dimensions. Except for the model of the dimension of control over work, since the minimum number of items for a dimension to be stable is three items [22]. Fourth, the elimination of items was stopped when optimal fit indices were achieved or when there was at least one item from each of the 20 sub-dimensions within the model. Fifth, if the final model presented low fit indices, it was decided to introduce correlation errors.

\section{Ethical aspects}

People who were included in the study had to read and sign the informed consent to voluntarily participate in the study. Likewise, participation was anonymous, and no information was included in the database that would allow them to be identified. Therefore, this study does not represent an ethical risk. The protocol has been approved by the Institutional Committee for Research Ethics of the National Institute of Health (No. RD 563-2015-OEI-OGITTOPE / INS). Necessary ethical care was maintained following the guidelines of the Declaration of Helsinki.

\section{Results}

\section{Participants}

The questionnaire was applied to a total of 1,707 workers, distributed throughout the country in three major geographic regions: Coast (Lima, Ica, La Libertad, and Piura, with a proportion of 35\%), Highlands (Arequipa, Huánuco, Junín, Pasco, Huancavelica, and Cuzco, representing 33.4\%) and Rainforest (San Martín, Ucayali, Madre de Dios, and Loreto, representing $31.6 \%$ of the sample).

The highest proportion of the population were males (61\%), and aged under $31(42 \%)$, and only a minority were over 45 years of age (17.3\%). Regarding their education, $29.6 \%$ of the sample had completed university education, followed by those with a complete technical and complete secondary education ( $19.2 \%$ and $18 \%$ respectively), and only $1.5 \%$ had incomplete primary education.

\section{One-dimensional models}

Seventeen of the 20 one-dimensional models presented adequate fit indices (see Table 1). It should be noted that eight of the seventeen one-dimensional models evaluated presented high RMSEA values. 
Table 1

Adjustment indices of the CENSOPAS-COPSOQ one-dimensional models.

\begin{tabular}{|c|c|c|c|c|c|c|c|c|c|}
\hline No. & Sub-dimensions & $\begin{array}{l}\mathrm{N}^{\circ} \\
\text { items }\end{array}$ & $x^{2}$ & $g l$ & CFI & SRMR & $\begin{array}{l}\text { RMSEA } \\
{[90 \% \mathrm{Cl}]}\end{array}$ & $\mathbf{a}$ & $\omega$ \\
\hline 1 & $\begin{array}{l}\text { Quantitative } \\
\text { requirements }\end{array}$ & 4 & 6.5 & 2 & 0.999 & 0.013 & $\begin{array}{l}0.036 \\
{[0.007-} \\
0.069]\end{array}$ & 0.67 & 0.71 \\
\hline 2 & Pace of work & 3 & 0 & 0 & 1 & 0 & 0 & 0.59 & 0.62 \\
\hline 3 & Emotional demands & 4 & 71.9 & 2 & 0.978 & 0.037 & $\begin{array}{l}0.143 \\
{[0.116-} \\
0.173]\end{array}$ & 0.74 & 0.74 \\
\hline 4 & $\begin{array}{l}\text { Demands to hide } \\
\text { emotions }\end{array}$ & 4 & 143.4 & 2 & 0.916 & 0.07 & $\begin{array}{l}0.204 \\
{[0.176-} \\
0.233]\end{array}$ & 0.63 & 0.65 \\
\hline 5 & Double presence & 4 & 121.3 & 2 & 0.993 & 0.027 & $\begin{array}{l}0.187 \\
{[0.160-} \\
0.216]\end{array}$ & 0.88 & 0.88 \\
\hline 6 & Influence & 4 & 20.6 & 2 & 0.999 & 0.011 & $\begin{array}{l}0.074 \\
{[0.047-} \\
0.104]\end{array}$ & 0.83 & 0.84 \\
\hline 7 & $\begin{array}{l}\text { Development } \\
\text { possibilities }\end{array}$ & 4 & 39.5 & 2 & 0.992 & 0.025 & $\begin{array}{l}0.105 \\
{[0.078-} \\
0.135]\end{array}$ & 0.74 & 0.75 \\
\hline 8 & Sense of work & 3 & 0 & 0 & 1 & 0 & 0 & 0.85 & 0.85 \\
\hline 9 & $\begin{array}{l}\text { Social support from } \\
\text { peers }\end{array}$ & 3 & 0 & 0 & 1 & 0 & 0 & 0.78 & 0.78 \\
\hline 10 & $\begin{array}{l}\text { Social support from } \\
\text { superiors }\end{array}$ & 3 & 0 & 0 & 1 & 0 & 0 & 0.90 & 0.90 \\
\hline 11 & Leadership quality & 4 & 96.3 & 2 & 0.998 & 0.015 & $\begin{array}{l}0.166 \\
{[0.139-} \\
0.195]\end{array}$ & 0.92 & 0.92 \\
\hline 12 & Group sentiment & 3 & 0 & 0 & 1 & 0 & 0 & 0.86 & 0.86 \\
\hline 13 & Predictability & 2 & & & & & & & \\
\hline 14 & Role clarity & 4 & 190.9 & 2 & 0.953 & 0.06 & $\begin{array}{l}0.235 \\
{[0.208-} \\
0.264]\end{array}$ & 0.74 & 0.75 \\
\hline 15 & Role conflict & 4 & 38.8 & 2 & 0.99 & 0.029 & $\begin{array}{l}0.104 \\
{[0.077-} \\
0.134]\end{array}$ & 0.68 & 0.70 \\
\hline 16 & Recognition & 3 & 0 & 0 & 1 & 0 & 0 & 0.84 & 0.85 \\
\hline
\end{tabular}




\begin{tabular}{|c|c|c|c|c|c|c|c|c|c|}
\hline No. & Sub-dimensions & $\begin{array}{l}\mathrm{N}^{\circ} \\
\text { items }\end{array}$ & $x^{2}$ & $g l$ & CFI & SRMR & $\begin{array}{l}\text { RMSEA } \\
{[90 \% \mathrm{Cl}]}\end{array}$ & $a$ & $\omega$ \\
\hline 17 & Job insecurity & 2 & & & & & & & \\
\hline 18 & $\begin{array}{l}\text { Insecurity about } \\
\text { working conditions }\end{array}$ & 4 & 38.9 & 2 & 0.996 & 0.02 & $\begin{array}{l}0.104 \\
{[0.077-} \\
0.134]\end{array}$ & 0.84 & 0.84 \\
\hline 19 & Justice & 4 & 15.4 & 2 & 0.998 & 0.012 & $\begin{array}{l}0.063 \\
{[0.036-} \\
0.094]\end{array}$ & 0.80 & 0.80 \\
\hline 20 & Vertical trust & 3 & 0 & 0 & 1 & 0 & 0 & 0.78 & 0.79 \\
\hline
\end{tabular}

Sixteen of the 20 one-dimensional models presented optimal values of internal consistency (reliability). However, the model of "work rhythm" and "demand to hide emotions" showed slightly low internal consistency values (see Table 1).

The dimensions of "predictability" and "insecurity about employment" did not present adjustment indices or internal consistency values since a minimum of 3 items per dimension is required. Therefore, these two one-dimensional models were not considered for this analysis. This does not affect the validity of these two dimensions since they were evaluated in the following stages of the analysis.

\section{Multidimensional models}

It was identified that all second-order models presented adequate adjustment indices, except the model of "psychological demands at work", which presented low adjustment indices. Therefore, correlated errors were used for this second-order model, finding that the model that correlates four pairs of errors was the most appropriate and parsimonious $(\mathrm{gl}=82 ; \mathrm{CFI}=0.900 ; \mathrm{SRMR}=0.071)$. It should be noted that all the models presented high RMSEA values.

It was identified that all second-order models presented optimal internal consistency values in all cases (see Table 2). It should be noted that the models that presented correlated errors and the fit indices were adjusted for errors. The selected models are graphically represented in Supplementary Materials 1 to 6 . 
Table 2

CENSOPAS-COPSOQ second-order models adjustment indices.

\begin{tabular}{|c|c|c|c|c|c|c|c|c|}
\hline Dimensions & $\begin{array}{l}\mathrm{N}^{\circ} \\
\text { items }\end{array}$ & $x^{2}$ & $g l$ & CFI & SRMR & RMSEA & $\begin{array}{l}\Omega \\
\text { hierarchical }\end{array}$ & $\begin{array}{l}\text { Correlated } \\
\text { errors }\end{array}$ \\
\hline $\begin{array}{l}\text { Psychological } \\
\text { demands at work }\end{array}$ & 15 & 3020.0 & 86 & 0.826 & 0.091 & $\begin{array}{l}0.142 \\
{[0.137-} \\
0.146]\end{array}$ & 0.94 & - \\
\hline $\begin{array}{l}\text { Psychological } \\
\text { demands at work }\end{array}$ & 15 & 2514.2 & 85 & 0.856 & 0.084 & $\begin{array}{l}0.130 \\
{[0.125-} \\
0.134]\end{array}$ & $0.94^{\mathrm{a}}$ & $\begin{array}{l}\text { Item } 26 \mathrm{f} \\
\text { and } 26 \mathrm{~m}\end{array}$ \\
\hline \multirow[t]{2}{*}{$\begin{array}{l}\text { Psychological } \\
\text { demands at work }\end{array}$} & \multirow[t]{2}{*}{15} & \multirow[t]{2}{*}{1990.4} & \multirow[t]{2}{*}{84} & \multirow[t]{2}{*}{0.887} & \multirow[t]{2}{*}{0.075} & \multirow[t]{2}{*}{$\begin{array}{l}0.116 \\
{[0.111-} \\
0.120]\end{array}$} & \multirow[t]{2}{*}{$0.94^{\mathrm{a}}$} & $\begin{array}{l}\text { Item } 26 f \\
\text { and } 26 \mathrm{~m}\end{array}$ \\
\hline & & & & & & & & $\begin{array}{l}\text { Item } 25 f \\
\text { and } 26 \mathrm{k}\end{array}$ \\
\hline \multirow[t]{3}{*}{$\begin{array}{l}\text { Psychological } \\
\text { demands at work }\end{array}$} & \multirow[t]{3}{*}{15} & \multirow[t]{3}{*}{1870.9} & \multirow[t]{3}{*}{83} & \multirow[t]{3}{*}{0.894} & \multirow[t]{3}{*}{0.073} & \multirow[t]{3}{*}{$\begin{array}{l}0.113 \\
{[0.108-} \\
0.117]\end{array}$} & \multirow[t]{3}{*}{$0.94^{\mathrm{a}}$} & $\begin{array}{l}\text { Item } 26 f \\
\text { and } 26 \mathrm{~m}\end{array}$ \\
\hline & & & & & & & & $\begin{array}{l}\text { Item } 25 f \\
\text { and } 26 \mathrm{k}\end{array}$ \\
\hline & & & & & & & & $\begin{array}{l}\text { Item 25a } \\
\text { and } 25 b\end{array}$ \\
\hline \multirow[t]{4}{*}{$\begin{array}{l}\text { Psychological } \\
\text { demands at work }\end{array}$} & \multirow[t]{4}{*}{15} & \multirow[t]{4}{*}{1777.9} & \multirow[t]{4}{*}{82} & \multirow[t]{4}{*}{0.900} & \multirow[t]{4}{*}{0.071} & \multirow[t]{4}{*}{$\begin{array}{l}0.110 \\
{[0.106-} \\
0.115]\end{array}$} & \multirow[t]{4}{*}{$0.94^{\mathrm{a}}$} & $\begin{array}{l}\text { Item } 26 f \\
\text { and } 26 \mathrm{~m}\end{array}$ \\
\hline & & & & & & & & $\begin{array}{l}\text { Item } 25 f \\
\text { and } 26 k\end{array}$ \\
\hline & & & & & & & & $\begin{array}{l}\text { Item 25a } \\
\text { and } 25 b\end{array}$ \\
\hline & & & & & & & & $\begin{array}{l}\text { Item } 26 \mathrm{j} \\
\text { and } 26 \mathrm{k}\end{array}$ \\
\hline $\begin{array}{l}\text { Work-family } \\
\text { conflict }\end{array}$ & 4 & 121.3 & 2 & 0.993 & 0.027 & $\begin{array}{l}0.187 \\
{[0.160-} \\
0.216]\end{array}$ & 0.88 * & - \\
\hline Control over work & 11 & 587.4 & 41 & 0.98 & 0.051 & $\begin{array}{l}0.088 \\
{[0.082-} \\
0.095]\end{array}$ & 0.74 & - \\
\hline $\begin{array}{l}\text { Social support and } \\
\text { quality of } \\
\text { leadership }\end{array}$ & 23 & 3419.3 & 223 & 0.955 & 0.071 & $\begin{array}{l}0.092 \\
{[0.089-} \\
0.094]\end{array}$ & 0.87 & - \\
\hline $\begin{array}{l}\text { Work } \\
\text { compensation }\end{array}$ & 9 & 431.6 & 24 & 0.984 & 0.044 & $\begin{array}{l}0.100 \\
{[0.092-} \\
0.108]\end{array}$ & 0.87 & - \\
\hline
\end{tabular}




\begin{tabular}{|c|c|c|c|c|c|c|c|c|}
\hline Dimensions & $\begin{array}{l}N^{\circ} \\
\text { items }\end{array}$ & $x^{2}$ & $g l$ & CFI & SRMR & RMSEA & $\begin{array}{l}\Omega \\
\text { hierarchical }\end{array}$ & $\begin{array}{l}\text { Correlated } \\
\text { errors }\end{array}$ \\
\hline Social capital & 7 & 665.2 & 12 & 0.963 & 0.075 & $\begin{array}{l}0.179 \\
{[0.167-} \\
0.190]\end{array}$ & 0.89 & - \\
\hline
\end{tabular}

\section{A short version of the instrument}

To develop the short version of the instrument, items of each first-order dimension were eliminated sequentially (supplementary material 7), until the most stable versions of the instrument were left. The most stable versions, with better fit indices and internal consistency, are presented in Table 3. Although all the models of the short version presented optimal fit indices, the seven-item model of "social support and leadership quality" has high RMSEA values. These values improve when the items corresponding to "peer social support" (item 28a) and "group feeling" (item 28e) are related, reaching optimal values ( $\mathrm{gl}=13 ; \mathrm{CFI}$ $=0.98 ;$ SRMR $=0.03 ;$ RMSEA $=0.08$ ).

Table 3

Adjustment indices of the short version of the CENSOPAS-COPSOQ.

\begin{tabular}{|c|c|c|c|c|c|c|c|c|c|}
\hline Dimensions & $\begin{array}{l}\mathrm{N}^{\circ} \\
\text { original } \\
\text { items }\end{array}$ & $\begin{array}{l}\text { Reduced } \\
\text { version }\end{array}$ & $x^{2}$ & $d f$ & CFI & SRMR & RMSEA & $\mathbf{a}$ & $\Omega$ \\
\hline $\begin{array}{l}\text { Psychological } \\
\text { demands at } \\
\text { work }\end{array}$ & 15 & 7 & 184.8 & 14 & 0.975 & 0.4 & $\begin{array}{l}0.085 \\
{[0.074-} \\
0.096]\end{array}$ & 0.79 & 0.80 \\
\hline $\begin{array}{l}\text { Work-family } \\
\text { conflict }\end{array}$ & 4 & 3 & 0 & 0 & 1 & 0 & $\begin{array}{l}0.000 \\
{[0.000-} \\
0.000]\end{array}$ & 0.87 & 0.87 \\
\hline $\begin{array}{l}\text { Control over } \\
\text { work }\end{array}$ & 11 & 5 & 56.0 & 5 & 0.993 & 0.026 & $\begin{array}{l}0.077 \\
{[0.060-} \\
0.096]\end{array}$ & 0.73 & 0.74 \\
\hline $\begin{array}{l}\text { Social support } \\
\text { and quality of } \\
\text { leadership }\end{array}$ & 23 & 7 & 287.9 & 14 & 0.962 & 0.046 & $\begin{array}{l}0.107 \\
{[0.097-} \\
0.118]\end{array}$ & 0.74 & 0.75 \\
\hline $\begin{array}{l}\text { Work } \\
\text { compensation }\end{array}$ & 9 & 5 & 24.5 & 5 & 0.999 & 0.018 & $\begin{array}{l}0.048 \\
{[0.030-} \\
0.068]\end{array}$ & 0.81 & 0.85 \\
\hline Social capital & 7 & 4 & 16.1 & 2 & 0.998 & 0.011 & $\begin{array}{l}0.064 \\
{[0.038-} \\
0.095]\end{array}$ & 0.81 & 0.82 \\
\hline
\end{tabular}


It should be noted that all the models of the short version have optimal reliability values (see Table 3 ). The selected models are graphically represented in Supplementary Materials 8 to 13.

The items of the medium-version and short-version in Spanish can be found in Supplementary Material 14.

\section{Discussion}

\section{Main conclusions and meaning of the results}

The CENSOPAS-COPSOQ presented evidence of validity and reliability for the medium version and the short version, therefore its use could be recommended in the Peruvian population to assess occupational psychosocial risks. The goodness of fit indices supports the evidence of the validity by internal structure, while the internal consistency coefficients of alpha and omega support the reliability of the measurement for both versions.

\section{Contrasting the findings with the existing literature}

Different studies evaluated the measurement properties of the COPSOQ, using heterogeneous analysis methods and providing results that included different factorial solutions both in the number of items and in the number of dimensions.

Two studies were identified that present inadequate analysis methods, which suggested unstable factor solutions. In Spain, the validity of the COPSOQ-ISTAS-21 in workers was analyzed through a factor analysis with varimax rotation, and the internal consistency of the model was evaluated through the Alpha coefficient [24]. However, this rotation method used was not adequate since it assumed that the items and dimensions are independent, which does not happen within the psychological variables since they are closely related to each other [25], even more in an instrument with such factorial complexity (i.e., with a large number of dimensions and subdimensions). In this Spanish study, 27 subdimensions were found, possibly due to the use of an analysis method that does not conform to the nature of the variables (categorical-ordinal). The short version of the instrument they presented had 38 items [24], which represents 7 more items than the one presented in our study. On the other hand, a study carried out in Brazil validated the average version of the COPSOQ-ISTAS-21 II in university workers [26]. In this study, the authors state that they used confirmatory factor analysis, exploratory factor analysis, and reliability analysis by internal consistency [26], managing to identify a factorial model composed of 21 subdimensions that grouped 70 items. However, in the analysis plan of their article, they point out that they used analysis by principal components, varimax rotation, and the number of dimensions was determined with the eigenvalue. This method of analysis is not recommended as it is highly subjective and can overestimate the number of dimensions [25].

Two other studies identified four-dimensional models, which diverges from our findings where six dimensions were identified in the Peruvian population. A Persian study by COPSOQ evaluated the short 
version of the instrument [27], finding through confirmatory factor analysis a total of 4 dimensions (32 items): quality of leadership, social support from supervisors, rewards, justice and respect, trust, and predictability (dimension 1), self-rated health, burnout, stress, work-family conflict and emotional demands (dimension 2), the meaning of work, commitment to the workplace, influence at work and role clarity (dimension 3), and offensive behavior (dimension 4). Unlike the CENSOPAS-COPSOQ (our study), the Persian study by Aminian et al., collapses dimensions to achieve a more stable factorial solution. However, conceptually they maintain the same indicators as our study. On the other hand, a study validated the French version of the COPSOQ based on the short version in the Danish language [28]. Through exploratory factor analysis, only 4 dimensions were presented ("interpersonal relationships and leadership", "influence and development", "tension", and "demands") with 32 items. This version is similar in the number of items that are proposed in our study for the short version.

Two other studies argued that a five-dimensional version is more stable compared to other factorial solutions. One of them adapted the medium version of the COPSOQ to Persian and concluded that the items were grouped into 20 subdimensions[29], just like in our model. However, in this study, these subdimensions were grouped into only 5 dimensions (Type of production and tasks, Organization and content of work, Interpersonal relationships and leadership, Work-individual interaction, and Health and well-being) [29]. Likewise, a study that evaluated the validity of the COPSOQ in professional drivers in Spain also reported a better factor solution with 5 dimensions ("Demands", "Influence and development", "Interpersonal relationships and leadership", "Job Insecurity" and "Strain ")[30]. These two studies present similar results to each other and by what our research identified since their dimensions are very similar to those proposed in our study.

A Chilean study carried out a validity and reliability analysis for the short version of the COPSOQ-ISTAS21, which they called SUSESO-ISTAS21 [31]. This study proposed a factorial structure of 5 dimensions ("Psychological demands"; "work and skills development"; "social support in the company and quality of leadership"; "compensation" and "double presence") with a total of 20 items. However, this structure composed of 5 dimensions did not present adequate adjustment indices (CFI = 0.795; $\mathrm{TLI}=0.762$; RMSEA =0.080)[19]. Despite presenting problems in its validity, it did achieve adequate internal consistency coefficients $(a>0.70)$ [23]. Therefore, although the instrument presents evidence of reliability, its factorial structure is unstable, and a correlated five-dimensional solution might not be the most appropriate.

The COPSOQ studies have presented heterogeneous factor structures and each one has obtained different dimensions and different numbers of items, according to the characteristics of their populations.

Also, measurement properties have been evaluated in various ways such as exploratory and confirmatory factor analyses, and some studies have used poorly recommended analytical methods that could lead to unstable results $[24,26]$. 
It should be noted that our study provides the use of second-order models, which allows a global score to be obtained by dimension and considers the 20 sub-dimensions within its structure. Therefore, we consider that our study provides a new approach to the available evidence from COPSOQ-ISTAS21 and is renamed CENSOPAS-COPSOQ.

The evidence presented corresponds to the second edition of COPSOQ; however, it should be noted that the third edition of COPSOQ was published in December 2019 [32]. The third edition adds a set of mandatory core items that must be included in all versions of the instrument (short, medium, or long), regardless of the country or context that adapts the scale. This will allow future studies conducted with the third edition of COPSOQ to have a constant set of items in all versions, which will allow comparisons to be made between countries and versions. This represents an important advance for the measurement of psychosocial risks because it will allow knowing the most appropriate items to the context but respecting a set of mandatory core items.

\section{Strengths and limitations}

Our CENSOPAS-COPSOQ study had a representative sample of workers from different economic activities and regions of Peru, allowing the representativeness of workers with different characteristics. However, the present study is not without limitations. First, evaluations using bifactor models, ESEM, or analysis of invariance could not be carried out, since there sample size was insufficient to make the models converge; so, there could be other factorial solutions that could be more stable using these models. Second, although it collects information from different participants, the selection strategy was nonprobabilistic, so the results could not be generalized to the entire Peruvian territory. Third, CENSOPASCOPSOQ collects the information on the psychosocial risks at work perceived by the worker, however, an identification of the psychosocial risk at the workplace was not carried out, to corroborate the perception of the worker. Fourth, it was not possible to apply other instruments that assess occupational psychosocial risks, which allows other validity evidence to be presented as evidence of relationship with other variables of the CENSOPAS-COPSOQ.

\section{Implications for public health and decision-making}

The COPSOQ is an instrument used in different contexts and countries to assess psychosocial risks at work. Therefore, it is a valid and reliable tool that would allow directing public policies and periodic evaluations for work centers of 25 people or less with the short version (31 items), as well as for work centers with more than 25 workers with the medium version (69 items). Other countries have used COPSOQ to design and evaluate their labor policies [10], therefore, this instrument can be used in Peru as a tool to direct decision-making in occupational and occupational health.

The CENSOPAS-COPSOQ could be used to evaluate the effect of organizational or labor interventions since it would allow seeing if the safety and risk management strategies applied in the workplace have a positive or protective effect on the health of the workers. workers, by carrying out evaluations before and after the interventions. 


\section{Conclusions}

The CENSOPAS-COPSOQ is an instrument with sufficient evidence of validity and reliability in its medium and short version, so its use is recommended in Peruvian work centers to identify, to assess and prevent psychosocial occupational risks.

\section{Declarations}

\section{Interest conflict}

The authors do not report any conflict of interest when conducting the study, analyzing the data, or writing the manuscript.

\section{Funding}

The study was funded by the National Institute of Health. The funders had no role in study design, data collection, analysis, decision to publish, or preparation of the manuscript.

\section{Availability of data and materials}

The database is available at https://doi.org/10.6084/m9.figshare.14138660

\section{Authors' contributions}

Martha Lucero, Iselle Sabastizagal, Jonh Astete, Miguel Burgos, and David Villarreal-Zegarra participated in the conception of the research idea, data collection, and writing of the final report. The technical assistance was provided by Salvador Moncada. All the authors have carried out the critical review of the paper and have approved the final version.

\section{Acknowledgments}

The authors acknowledge Luis Alberto Orneño Delgado for the translation of the manuscript into English.

\section{Ethics approval and consent to participate}

People who were included in the study had to read and sign the informed consent to voluntarily participate in the study. Likewise, participation was anonymous, and no information was included in the database that would allow them to be identified. Therefore, this study does not represent an ethical risk. The protocol has been approved by the Institutional Committee for Research Ethics of the National Institute of Health (No. RD 563-2015-OEI-OGITTOPE / INS). Necessary ethical care was maintained following the guidelines of the Declaration of Helsinki.

\section{Consent for publication}

Not applicable. 


\section{References}

1. Moreno Jiménez B: Factores y riesgos laborales psicosociales: conceptualización, historia y cambios actuales. Medicina y Seguridad del Trabajo 2011, 57:4-19.

2. Leka S, Griffiths A, Cox T, World Health Organization O, Environmental Health T: Work organisation and stress : systematic problem approaches for employers, managers and trade union representatives. Geneva: World Health Organization; 2003.

3. World Health Organization: PRIMA-EF : guidance on the European framework for psychosocial risk management : a resource for employer and worker representatives. Geneva: World Health Organization; 2008.

4. Kivimäki M, Kawachi l: Work Stress as a Risk Factor for Cardiovascular Disease. Current cardiology reports 2015, 17(9):630.

5. Holst GJ, Paarup HM, Baelum J: A cross-sectional study of psychosocial work environment and stress in the Danish symphony orchestras. International archives of occupational and environmental health 2012, 85(6):639-649.

6. Albertsen K, Rugulies R, Garde AH, Burr H: The effect of the work environment and performancebased self-esteem on cognitive stress symptoms among Danish knowledge workers. Scand J Public Health 2010, 38(3 Suppl):81-89.

7. Nübling M, Vomstein M, Schmidt SG, Gregersen S, Dulon M, Nienhaus A: Psychosocial work load and stress in the geriatric care. BMC public health 2010, 10:428.

8. van den Berg TI, Elders LA, de Zwart BC, Burdorf A: The effects of work-related and individual factors on the Work Ability Index: a systematic review. Occupational and environmental medicine 2009, 66(4):211-220.

9. Congreso de la República del Perú: Reglamento de la Ley № 29783, Ley de Seguridad y Salud en el Trabajo. In: DECRETO SUPREMO No 005-2012-TR. Peru; 2012.

10. Leka S, Jain A, World Health O: Health impact of psychosocial hazards at work: an overview. Geneva: World Health Organization; 2010.

11. Karasek R, Brisson C, Kawakami N, Houtman I, Bongers P, Amick B: The Job Content Questionnaire (JCQ): an instrument for internationally comparative assessments of psychosocial job characteristics. Journal of occupational health psychology 1998, 3(4):322-355.

12. Siegrist J, Starke D, Chandola T, Godin I, Marmot M, Niedhammer I, Peter R: The measurement of effort-reward imbalance at work: European comparisons. Social science \& medicine (1982) 2004, 58(8):1483-1499.

13. Kristensen TS, Hannerz H, Høgh A, Borg V: The Copenhagen Psychosocial Questionnaire-a tool for the assessment and improvement of the psychosocial work environment. Scandinavian journal of work, environment \& health 2005, 31(6):438-449.

14. Elo A-L, Skogstad A, Dallner M, Gamberale F, Hottinen V, Knardahl S: User's guide for the QPSNordic : General Nordic Questionnaire for psychological and social factors at work. Copenhagen: Nordic 
Council of Ministers.; 2000.

15. Burr H, Albertsen K, Rugulies R, Hannerz H: Do dimensions from the Copenhagen Psychosocial Questionnaire predict vitality and mental health over and above the job strain and effort-reward imbalance models? Scand J Public Health 2010, 38(3 Suppl):59-68.

16. Fernandes C, Pereira A: Exposure to psychosocial risk factors in the context of work: a systematic review. Revista de saude publica 2016, 50:24.

17. Moncada S, Utzet M, Molinero E, Llorens C, Moreno N, Galtés A, Navarro A: The copenhagen psychosocial questionnaire II (COPSOQ II) in Spain-a tool for psychosocial risk assessment at the workplace. American journal of industrial medicine 2014, 57(1):97-107.

18. Li CH: Confirmatory factor analysis with ordinal data: Comparing robust maximum likelihood and diagonally weighted least squares. Behavior research methods 2016, 48(3):936-949.

19. Hair JF, Anderson RE, Tatham RL, Black WC: Análisis multivariante, vol. 491: Prentice Hall Madrid; 1999.

20. Bentler PM: Comparative fit indexes in structural models. Psychol Bull 1990, 107(2):238-246.

21. Hu Lt, Bentler PM: Cutoff criteria for fit indexes in covariance structure analysis: Conventional criteria versus new alternatives. Structural Equation Modeling: A Multidisciplinary Journal 1999, 6(1):1-55.

22. Muñiz J: Introducción a la Psicometría: Teoría clásica y TRI. España: Ediciones Pirámide; 2018.

23. Viladrich C, Angulo-Brunet A, Doval E: A journey around alpha and omega to estimate internal consistency reliability. Anales de psicologia 2017, 33(3):755-782.

24. Moncada S, Llorens C, Navarro A, Kristensen TS: ISTAS21: Versión en lengua castellana del cuestionario psicosocial de Copenhague (copsoq). Archivos de Prevención de Riesgos Laborales 2005(8):18-29.

25. Lloret-Segura S, Ferreres-Traver A, Hernández-Baeza A, Tomás-Marco I: El análisis factorial exploratorio de los ítems: una guía práctica, revisada y actualizada. Anales de psicología 2014, 30(3):1151-1169.

26. Lima IAX, Parma GOC, Cotrim T, Moro ARP: Psychometric properties of a medium version of the Copenhagen Psychosocial Questionnaire (COPSOQ II) for southern Brazil. Work (Reading, Mass) 2019, 62(2):175-184.

27. Aminian M, Dianat I, Miri A, Asghari-Jafarabadi M: The Iranian version of the Copenhagen Psychosocial Questionnaire (COPSOQ) for assessment of psychological risk factors at work. Health promotion perspectives 2017, 7(1):7-13.

28. Dupret E, Bocéréan C, Teherani M, Feltrin M, Pejtersen JH: Psychosocial risk assessment: French validation of the Copenhagen Psychosocial Questionnaire (COPSOQ). Scand J Public Health 2012, 40(5):482-490.

29. Pournik O, Ghalichi L, TehraniYazdi A, Tabatabaee SM, Ghaffari M, Vingard E: Measuring psychosocial exposures: validation of the Persian of the copenhagen psychosocial questionnaire (COPSOQ). Medical journal of the Islamic Republic of Iran 2015, 29:221. 
30. Useche SA, Montoro L, Alonso F, Pastor JC: Psychosocial Work Factors, Job Stress and Strain at the Wheel: Validation of the Copenhagen Psychosocial Questionnaire (COPSOQ) in Professional Drivers. Frontiers in psychology 2019, 10:1531.

31. Mendoza-Llanos R, Moyano-Díaz E: Hacia la validación del SUSESO ISTAS 21 versión breve en trabajadores de hospitales públicos. Terapia psicológica 2019, 37(1):15-23.

32. Burr H, Berthelsen H, Moncada S, Nübling M, Dupret E, Demiral Y, Oudyk J, Kristensen TS, Llorens C, Navarro A et al: The Third Version of the Copenhagen Psychosocial Questionnaire. Safety and health at work 2019, 10(4):482-503.

\section{Supplementary Files}

This is a list of supplementary files associated with this preprint. Click to download.

- 4.Supplementmaterial.docx 